\title{
Veinte años pueden ser muchos o pueden ser pocos
} sí como la palabra tradición (o tradicional) es lo contrario de decrepitud, pasado ańoso, moldes fijos (jes lo más vivo y actual en la dinámica interior de las generaciones!), la palabra homenaje no debe aludir solo a lo acabado que permanece en el recuerdo sino, también, a una mirada proyectiva en donde la obra de un personaje notable o de una institución emblemática -por ejemplo- continúa recreándose y reactualizándose en el presente. Lo dicho viene al caso cuando nos referimos a la Oficina Central de Extensión Cultural y Proyección Social de nuestra Universidad que está cumpliendo su vigésimo aniversario uniendo -como lo pide el espíritu de la modernidad- las raíces del pasado con las expectativas del presente. Esta experiencia de auténtica pedagogía vital se ha ido fortificando y aún continúa con la misma fuerza del principio, hace veinte años.

Estas dos décadas de hermosas jornadas pedagógicas y artísticas nos ha cambiado la vida, igual que a los alumnos y a todas las personas que sintonizan con los principios de la Educación por el Arte: "Percepción, sensación y expresión para la comunicación plena"; "globalización de vivencias" y "explicación e interpretación de los fenómenos (unión de la ciencia y el arte)".

La pauta que marca el sentido humano, organizacional y ético de nuestra oficina, es la del autoaprendizaje cotidiano sobre la base de ser y de hacer aquello que se declara, que se enseña. Siendo así, nuestros profesores ofrecen charlas y conferencias; escriben artículos; actúan guiados por la conducta autónoma para el mejor desarrollo de la flexibilidad, la fluidez y la originalidad creadoras, y tienen amor por la investigación y la cultura en general.

La creatividad como forma de vida, postulado básico de la Educación por el Arte, representa, a la postre, el ideario de acción de toda nuestra universidad. Mediante la creatividad, en donde se subrayan los procesos personales sin desmerecer, obviamente, los resultados, se afirma la voluntad de actuar a través de una sostenida labor cultural y social desarrollada dentro y fuera de la Universidad: Cerro Azul, Trujillo, Ica, Santiago de Chuco, Manchay, entre otros. Igualmente, esta labor trascendente se visibiliza en las innumerables conferencias y exposiciones artísticas, así como en los festivales, encuentros, recitales, conciertos, etc., muchos de ellos con proyección internacional. Y está la Maestría en Educación por el Arte, la única en el Perú; y están, en fin, los elencos artísticos que recorren todo el país y aún el extranjero. 


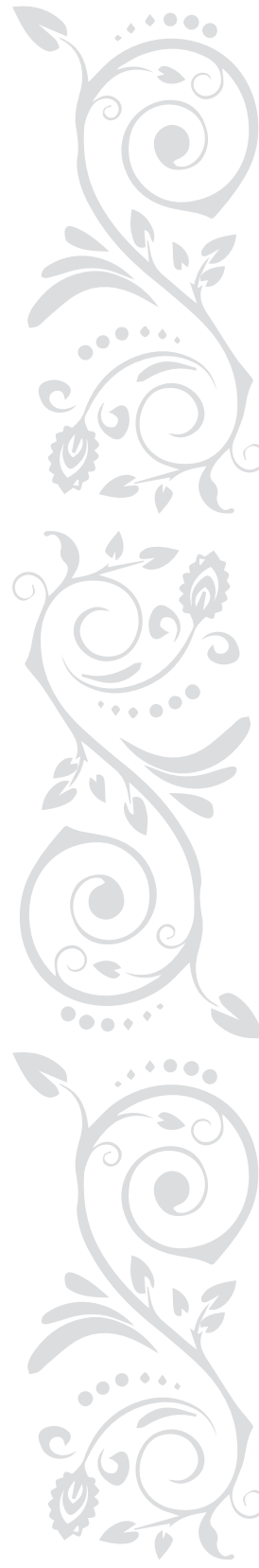

Hondo regocijo nos produce esta labor incesante. Representa el trabajo de una vocación que se consolidaría a principios de los ochenta cuando empezamos a esbozar los conceptos teóricos básicos de esta trascendente Educación. Fueron años largos de intensa actividad y de autoaprendizaje apoyados en la filosofía, psicología, sociología, estética, biología, historia, pedagogía, didáctica, etc. que sirvieron para consolidar, paralelamente, esa praxis y esa teoría que evitan el diletantismo y la ceguera. Esto lo verificamos en el propio actuar de nuestros docentes. Ellos son a través de su propia forma de ser, es decir, por causa del espíritu creativo que los distingue, que es el mejor estímulo para los alumnos. Y es que la creatividad como norma de vida conduce a esa ética del comportamiento basado en valores de libertad, de justicia, de solidaridad.

Debemos por todo ello sentirnos orgullosos de nuestra Universidad y de la labor realizada, pero, sin duda, el futuro estará siempre abierto para enfrentarnos a nuevos retos.

\section{II}

Tradición es la revista del Rectorado. Esto quiere decir que sus artículos no provienen solo de la Dirección de Extensión Cultural y Proyección Social sino de todos los estamentos de la Universidad. Pero el espíritu que ella recoge esta imbuido de esa "creatividad como forma de vida" que, en verdad, es el sello característico de toda nuestra Casa de Estudios. Así pues, el lector podrá leer la universalidad del pensamiento a través de ensayos múltiples y variados, referidos a la ciencia, el arte y la tecnología. Algunos títulos significativos son: "El poliedro académico universitario como símbolo de lo múltiple y unitario", de Iván Rodríguez Chávez; "Hacia una ciencia política de la liberación”, de Francisco Miró Quesada Rada; "Hanaqpachaq kusikuynin, música colonial religiosa andina", de Mario Mejía Huamán; "Desafíos de la investigación psicológica en el Perú ante el avance de la ciencia y la tecnología en el siglo XXI”, de Hugo Sánchez Carlessi; "Neurociencias moleculares en neuropsicología”, de Ana María Montero Doig; "Racismo, colonialidad e identidad. La escuela desde los maestros", de Pedro Jacinto Pazos; "La generación poética peruana del 59", de Eduardo Arroyo Laguna; "El colegio internacional de cirujanos y la universidad Ricardo Palma", de Manuel Huamán Guerrero; "El arte y las costumbres musicales en Puquio", de Boris Villegas Tincopa; "El licenciamiento de la Universidad Ricardo Palma. La experiencia exitosa del trabajo en equipo", de José Clemente Florez Barboza, Frank Paredes Rosales y Sonia Paredes López; y "La psicología del siglo XXI", de Gerardo Choque Martínez, entre otros.

\section{Manuel Pantigoso}

Director 